\title{
Equalização Fiscal e Crescimento Econômico: uma Análise do Fundo de Participação dos Estados Utilizando um Painel com Threshold
}

\section{Tax Equalization and Economic Growth: a Threshold Analysis on Brazilian State Participation Fund}

Luiz Carlos Ribeiro Neduziak* Fernando Motta Correia**

\begin{abstract}
Resumo: O presente ensaio tem por objetivo analisar como os estados brasileiros têm respondido, em termos de crescimento econômico per capita, aos gastos por categoria econômica, tendo em vista as transferências oriundas da União por meio do Fundo de Participação dos Estados e Distrito Federal (FPE). A literatura acerca do tema da equalização fiscal tem enfatizado os lados positivo e negativo da adoção de programas de equalização fiscal sobre o desempenho econômico dos entes subnacionais. Para se avaliar o impacto do regime de transferências sobre a trajetória de crescimento econômico per capita dos estados brasileiros, adota-se o modelo de Devarajan, Swarrop e Zou (1996) acrescido de um efeito threshold, tal como descrito por Hansen (1999). A ideia é capturar distintos efeitos dos gastos públicos sobre a taxa de crescimento econômico per capita a depender do grau de dependência orçamentária, nos diferentes entes estaduais. Os resultados da pesquisa apontam que os estados com maior grau de dependência em relação às transferências da União são aqueles que apresentam uma correlação negativa entre a razão investimento/gasto com pessoal (IGP) e a taxa de crescimento do PIB real.
\end{abstract}

Palavras-chave: Transferência intergovernamental. Crescimento econômico. Estados brasileiros.

\begin{abstract}
The paper aims to analyze how Brazilian states have responded in terms of economic growth per capita to transfers coming from federal government program, through the Participation Fund of the States and the Federal District (FPE). The literature on tax equalization has emphasized the positive and negative side of the adoption of fiscal equalization programs on the economic performance of subnational entities, such as municipalities and states. To measure the impact of the scheme of transfers on the GDP per capita growth of Brazilian states, one adopts the model of Devarajan, Swarrop and Zou (1996) together with a threshold effect, as described in Hansen (1999). The cornerstone of the paper was to capture possible different effects of public spending on the rate of economic growth per capita depending on the level of budgetary dependence on different state entities. The econometric results suggest a double output: on the one hand, Brazilian

\footnotetext{
* $\quad$ Doutor em Desenvolvimento Econômico pela Universidade Federal do Paraná (UFPR). Professor do Departamento de Economia da Pontifícia Universidade Católica do Paraná (PUCPR). E-mail: luiz_neduziakov@hotmail.com do Departamento de Economia da Universidade Federal do Paraná (UFPR). E-mail: fmottabr@ yahoo.com.br
}

* Doutor em Desenvolvimento Econômico pela Universidade Federal do Paraná (UFPR). Professor
\end{abstract}


states with higher degree of dependence on transfers from the Union are those that present a negative correlation between the ratio Investment/Personnel Expenditure (IGP) and the real GDP growth rate and, on the other hand, Brazilian states with lower dependence on Union transfers show a positive association between GDP growth and Investment/Spending Personnel (IGP).

Keywords: Intergovernmental relations. Economic growth. Brazilian States.

JEL Classification: $\mathrm{H} 77 ; \mathrm{O} 40 ; \mathrm{H} 72$.

\section{Introdução}

A Constituição Federal de 1988 (CF), nos artigos 145 e 162, estabelece as competências tributárias da União, estados e municípios bem como as respectivas responsabilidades políticas e sociais desses entes federativos. O Pacto Federativo (PF) delimitou a fronteira tributária do que deveria pertencer a cada ente federativo por meio dos Fundos de Participação dos Estados e Municípios e dos Fundos Constitucionais. Desse modo, o objetivo primaz do PF foi a descentralização da receita tributária em detrimento da União, visando o fortalecimento da capacidade tributária dos entes subnacionais, sobretudo dos mais pobres, e a redução das disparidades fiscais locais e regionais (BRASIL, 1988).

O regime de transferências dos governos centrais para os subnacionais tem sido amplamente utilizado em países desenvolvidos (por exemplo, Austrália, Canadá, Alemanha, Finlândia, Dinamarca, Noruega, Suécia e Suíça) e na maioria dos países em desenvolvimento (Brasil, Índia, Tailândia e Polônia). O principal objetivo da equalização fiscal é reduzir as dissimilaridades regionais em termos de capacidade de prestação de serviços públicos, ou seja, da expansão da restrição orçamentária por meio da ampliação das receitas tributárias - uma vez que parte desse potencial desequilíbrio é resultante da autonomia própria de estruturas federativas -, bem como diminuir o custo associado à prestação e provisão de serviços públicos, visando o atendimento das necessidades básicas locais. Em outras palavras, a equalização fiscal é uma transferência de recursos com fins puramente distributivos dos entes tributo-superavitários, e que apresentam baixo custo de provisão dos serviços públicos, para os entes tributo-deficitários e com alto custo de provisão do serviço público (ORGANISATION FOR ECONOMIC CO-OPERATION AND DEVELOPMENT, 2007).

A literatura tem enfatizado o lado positivo e negativo da adoção de programas de equalização fiscal. No primeiro caso, podem-se mencionar: a) a equidade horizontal, que garanta o acesso de entes de diferentes jurisdições a um mesmo padrão de acesso a bens e serviços públicos sob o signo "igual tratamento para jurisdições horizontalmente iguais" (BOADWAY, 2004); b) a integração das economias regionais à economia nacional via convergência fiscal; c) a garantia da união política dos entes subnacionais (SHAH, 2014); d) a eficiência fiscal, tendo 
em vista a mitigação do fenômeno de congestionamento decorrente do processo migratório (BUCHANAN; GOETZ, 1972); e) a estabilidade macroeconômica, através da criação de mecanismos capazes de acentuar a simetria regional a choques econômicos (KONRAD; SEITZ, 2003). No segundo caso, é possível citar: o desincentivo para que os estados e regiões desenvolvam pouco suas economias e bases de arrecadação, ou seja, um impacto negativo da equalização sobre o crescimento econômico (BLOCHLIGER; CHARBIT, 2008; GARNAUT; FITZGERALD, 2002); o mau uso dos instrumentos de política tributária com aumento excessivo dos tributos e expansão dos gastos em consumo em detrimento dos gastos em educação e investimento (BARETTI; HUBER; LICHTBLAU, 2002); e a insustentabilidade da política fiscal com redução na qualidade do gasto público (WURZEL, 2003).

O programa de equalização fiscal brasileiro insere-se no tipo vertical ou paternal, caracterizado pela facilidade de implementação de suas diretrizes e pelo respeito ao objetivo primaz do pacto federativo, que é a integração e cooperação dos entes subnacionais. A transferência de receitas, nesse tipo de regime, ocorre de cima para baixo, ou seja, da União para os estados, ou, dos estados para os municípios. Entretanto, a equalização vertical traz consigo alguns condicionantes ruins, a exemplo do incentivo à prática de lobby (e corrupção), ineficiências na produção e provisão de bens e serviços públicos e desincentivos à melhoria na qualidade do gasto público e percepção de receitas tributárias de forma eficiente (REINGEWERTZ, 2014; SHAH, 2014). Desse modo, o papel desempenhado pelo governo central, a União, ao transferir receitas de tributos, pode distorcer a estrutura de incentivos com que os entes federativos se defrontam, influenciando a alocação eficiente de recursos ou a qualidade do gasto público (BOADWAY, 1982).

Tendo como pano de fundo a discussão acerca dos impactos da equalização fiscal sobre o comportamento alocativo dos entes subnacionais, o objetivo deste artigo é analisar como os estados brasileiros têm respondido, em termos de crescimento econômico per capita, às transferências oriundas da União por meio do Fundo de Participação dos Estados e Distrito Federal (FPE). Para a realização do estudo econométrico, foi elaborado o índice de dependência dos estados e Distrito Federal (Idep) por meio da razão entre o FPE e a receita corrente líquida (RCL).

Para se analisar o efeito do Idep sobre o crescimento do PIB per capita dos estados brasileiros, adota-se como base o modelo analítico de Devarajan, Swarrop e Zou (1996). O modelo destoa por não tecer considerações a priori acerca de quais gastos públicos são produtivos ou improdutivos, ou seja, quais gastos impactam, positivamente ou negativamente, o crescimento econômico. Para a estimação empírica desse modelo, adota-se o modelo de efeitos fixos com threshold, tal como descrito por Hansen (1998), no período de 2000 a 2011. Para compor o modelo, foram utilizados os seguintes gastos por função presentes na Execução Orçamentária do Tesouro Nacional: a) educação; b) indústria, comércio e servi- 
ços; c) assistência e previdência; e d) saúde e saneamento. Essas rubricas foram selecionadas, tendo em vista que, para a implementação empírica do painel com efeito threshold, exige-se que seja balanceado.

O modelo de Hansen (1998) permite a inclusão de uma variável de threshold (Idep) e outra dependente do regime de threshold (IGP), possibilitando, assim, uma análise mais articulada e robusta entre elas e a variável dependente (crescimento econômico). Uma vez capturada a existência de diferentes regimes, o que gera diferentes dinâmicas entre a taxa de crescimento econômico e o IGP, espera-se que a mesma dinâmica ocorra ao introduzir-se a razão ICMS/RCL, tendo em vista que os estados mais dependentes das transferências da União são aqueles que apresentam menor capacidade tributária.

Além desta introdução, este artigo apresenta mais quatro seções: a seção 2 traz as principais contribuições da literatura acerca do equacionamento fiscal e os impactos da adoção desse tipo de regime sobre o comportamento de entes subnacionais; a seção 3 aborda as principais características do federalismo fiscal brasileiro, incluindo o tema das transferências fiscais brasileiras e o FPE; a seção 4 apresenta o modelo de efeitos fixos com threshold de Hansen (1998) e os resultados do modelo econométrico; e a seção 5 tece as considerações finais.

\section{Equalização Fiscal e Transferências Intergovernamentais: uma Visão Geral}

O sistema de equalização fiscal é considerado um dos principais pilares de convergência de renda entre estados e regiões de um mesmo país. O principal objetivo do sistema de transferências intergovernamentais é minimizar as diferenças no benefício fiscal líquido percebido pelos cidadãos pertencentes a regiões economicamente distintas de um mesmo país, sendo o benefício fiscal líquido a diferença entre o benefício oriundo do consumo de bens públicos menos o custo associado à produção e provisão desses bens, via pagamento de impostos. Portanto, o objetivo primaz das transferências é convergir a baixa capacidade de arrecadação tributária e o custo dos serviços públicos dos entes subnacionais visando o acesso igualitário dos cidadãos aos bens e serviços públicos essenciais (BUCHANAN, 1950; BOADWAY, 2001; GARNAUT; FITZGERALD, 2002).

Buchanan $(1950,1952)$ consagra o trabalho seminal de análise do ganho potencial oriundo das transferências intergovernamentais. Para o autor, o sistema de equalização fiscal deve estar presente na agenda dos governos centrais, principalmente na presença de distorções alocativas (ineficiência) entre estados e regiões. Esse argumento é amparado pela ideia de que uma estrutura descentralizada (federalista) pode às vezes levar a resultados ineficientes, do ponto de vista nacional, a exemplo da migração inter-regional de mão de obra e seu efeito con- 
gestionamento sobre a oferta de bens e serviços públicos das regiões ou estados mais produtivos. A contribuição de Buchanan é a semente para o desenvolvimento de trabalhos posteriores, cuja temática centra-se nos impactos de estruturas descentralizadas sobre a equidade e eficiência dos entes subnacionais (BUCHANAN; GOETZ, 1972; FLATTERS; HENDERSON; MIESZKOWSKI, 1974; BOADWAY; FLATTERS, 2004).

De acordo com Blochliger e Charbit (2008) e Buchanan (1950, 1952), o sistema de equalização fiscal pode desempenhar três importantes papéis:

a) de equidade horizontal, visando garantir o acesso de pessoas e empresas de diferentes jurisdições a serviços públicos de maneira proporcional ao que a maior carga tributária pudesse proporcionar de acordo com o lema "igual tratamento para jurisdições horizontalmente iguais". Boadway (2004) argumenta que a equidade fiscal é uma maneira de se implementar, na prática, a equidade horizontal, o que consiste, basicamente, em garantir às regiões menos desenvolvidas o acesso a recursos que as possibilitem convergir economicamente de acordo com sua estrutura de preferências;

b) de eficiência, visando corrigir, via transferências centrais, as ineficiências decorrentes de escolhas baseadas na estrutura fiscal e não produtiva de um estado, bem como o efeito congestionamento resultante do influxo de imigrantes que pode sobrecarregar a estrutura de provisão de bens e serviços públicos de uma determinada região (BUCHANAN; GOETZ, 1972);

c) de estabilidade macroeconômica, tendo em vista a pressuposição de que o governo central teria maiores condições de fazer frente a choques econômicos, uma vez que dispõe de uma maior dotação orçamentária. Em outras palavras, a equalização fiscal possibilitaria uma resposta mais simétrica dos estados ou regiões a choques do ciclo econômico (KONRAD; SEITZ, 2003).

Muitos arranjos de equalização fiscal podem ser delineados, refletindo a direção da equalização fiscal - horizontal ou vertical, e o tipo de diferença regional a ser equalizada - se nos custos ou nas receitas percebidas (BLOCHLIGER; CHARBIT, 2008). No primeiro caso, a equalização horizontal ou fraternal refere-se às transferências entre entes subnacionais, dos mais ricos para os mais pobres, por exemplo, enquanto que a vertical ou paternal reflete a transferência do governo central para jurisdições menores e subordinadas. Alguns exemplos de países que adotam a equalização horizontal são: Alemanha, Finlândia, Dinamarca, Noruega, Suíça, Suécia, Polônia e Brasil (SHAH, 2014). No segundo caso, a equalização de receitas está relacionada à equiparação da capacidade per capita de arrecadação tributária dos entes federativos, enquanto que a equalização de custos visa à redução dos custos associados ao provimento do serviço público. Exemplos de países que adotam esse tipo de regime: Austrália e Canada (SHAH, 2014). 
Boa parte da literatura tem ressaltado o efeito positivo das transferências de equalização sobre o resultado dos governos subnacionais, sem, entretanto, levar em consideração possíveis efeitos adversos da adoção desse regime. Boadway (2004) enfatiza, por exemplo, que a equalização para a estabilização pode gerar problemas de incentivos para as regiões por conta do timing inapropriado do uso de políticas, podendo acentuar o efeito do choque adverso (risco moral) ou, mesmo, gerar um problema de seleção adversa em função da assimetria de informação entre o governo central e os entes subnacionais. Analisando o caso canadense, Boadway e Hayashi (2004) encontram evidências de que o regime de equalização adotado por esse país tem aumentado a instabilidade da estrutura de receitas dos governos locais se comparado à ausência do sistema de equalização, violando o pressuposto da estabilidade. Wurzel (2003) demonstra haver um efeito perverso das transferências fiscais sobre o comportamento dos governos locais, uma vez que o financiamento dos gastos subnacionais, via transferências, acaba por impactar a sustentabilidade da política fiscal em decorrência das decisões discricionárias em relação aos custos e gastos fiscais, reduzindo, assim, a qualidade do gasto público.

Essa afirmação faz sentido na medida em que os gastos são mais sensíveis (ou mais descentralizados) em relação à variação das transferências do que as receitas propriamente ditas. Isto é, o regime de equalização fiscal pode, em certa medida, inflar o orçamento público central e subnacional, podendo gerar um comportamento explosivo da dívida pública. Em alguns casos, o regime de transferências pode ainda obstar o crescimento econômico dos entes subnacionais. O principal argumento estaria relacionado ao fato de que as jurisdições mais pobres não teriam incentivos para desenvolver suas economias e sua base de arrecadação, uma vez que estariam em uma posição mais leniente ao serem compensadas financeiramente pelo governo central (BLOCHLIGER; CHARBIT, 2008; GARNAUT; FITZGERALD, 2002). Nesse sentido, Checherita, Nickel e Rother (2009) encontram evidências de que o programa de transferências europeu tem arrefecido o crescimento econômico de ambas as regiões, pobres e ricas, da mesma maneira que tem promovido uma convergência tímida entre os países do bloco.

O regime de equalização fiscal pode ainda interferir na capacidade de arrecadação dos governos locais, uma vez que geraria distorções do ponto de vista da política tributária, o que, por sua vez, levaria a um regime de elevadas taxas tributárias e excessivo aumento nos gastos em bens de consumo em detrimento dos gastos em educação e investimento (KRAEMER, 1997; BARETTI; HUBER; LICHTBLAU, 2002; DAHLBY, 2002). 


\section{Federalismo Fiscal, Transferências Intergovernamentais e o Fundo de Par- ticipação dos Estados (FPE)}

Segundo Francisco Neto (2009), o ponto de partida para o estudo do federalismo fiscal, ou a análise econômica de governos descentralizados, é o reconhecimento de que existem certas atribuições econômicas que devem ser desempenhadas pelo governo central e outras pelos governos subnacionais, tendo como elo as finanças públicas. De acordo com Musgrave (1976), as atribuições econômicas típicas de governo são: a) a realocação de recursos econômicos, visando à produção e provisão de bens públicos; b) a promoção da distribuição de renda; e c) a manutenção da estabilidade macroeconômica.

Segundo Conti (2004), uma das principais ideias por trás do conceito de federalismo fiscal está relacionada à existência dos regimes democráticos, uma vez que se pressupõe maior participação das comunidades locais na definição das preferências públicas e no uso dos recursos tributários. A descentralização tributária poderia mesmo atuar como reveladora de preferências ao induzir os contribuintes a migrarem para regiões com melhor oferta de bens públicos e tributos. Esse mecanismo de seleção poderia acentuar a competitividade entre os entes subnacionais, melhorando a eficiência da administração pública e o bem-estar das comunidades (TIEBOUT, 1956).

Entretanto, mesmo não havendo mobilidade espacial dos contribuintes, os governos subnacionais podem deter maior informação acerca das preferências locais em detrimento do governo central. Nesse sentido, o teorema da descentralização de Oates (1972) afirma que os governos locais possuem maior informação em relação às preferências e necessidades das populações locais que os governos centrais. Desse modo, a oferta e provisão de bens públicos devem ser priorizadas por esses entes subnacionais, uma vez que o fazem de maneira mais eficiente que a provisão central.

Os antecedentes do federalismo fiscal brasileiro remontam pelo menos à instauração da República Liberal, em 1889. O período republicano passou por várias etapas de fechamento e abertura política, o que, por conseguinte, refletia-se na maneira pela qual a União se relacionava com os estados e municípios. O fim da ditadura militar e o início da redemocratização, o que culminou com a promulgação da $\mathrm{CF}$, marcam o fim de um período em que governadores e prefeituras estavam sujeitos aos auspícios do governo central, que havia centralizado recursos para levar adiante suas políticas de governo (CONTI, 2004; BARBOSA, 1998).

A promulgação da $\mathrm{CF}$ de 1988 dá continuidade a uma fase de elevada descentralização tributária, uma vez que houve ampla redistribuição de recursos em benefício dos estados e municípios, sobretudo em relação a estes, que apresenta- 
ram um considerável aumento de receita, desde o ano de $1980 .{ }^{1}$ Dessa forma, a Assembleia Constituinte consolidou e regulamentou um processo de descentralização tributária que principiara no início dos anos de 1980 (BARBOSA, 1998).

Os artigos 145 a 162 estabelecem as normas de partilha das receitas tributárias entre a União e os estados e municípios (BRASIL, 1988). O modelo federativo pressupõe a fragmentação política por meio da divisão da arrecadação tributária entre os entes federativos. Segundo o princípio constitucional da subsidiariedade, as unidades locais, sejam estados ou municípios, uma vez tendo condições de realizar atividades de qualquer natureza, devem fazê-lo por si próprias, sem a necessidade do poder central.

Tendo em vista a escassez de recursos subnacionais, a CF de 1988 adotou mecanismos de transferência destinados aos governos dos estados e municípios por meio da repartição de receitas tributárias com os entes menores, que, segundo a Carta Magna, não apresentavam capacidade própria de geração de recursos, além do que, com o tempo, essas unidades menores passaram a receber maiores atribuições locais no que toca à produção de bens públicos e implementação de políticas (FERREIRA JÚNIOR, 2006; REZENDE, 2006). ${ }^{2}$

Embora haja a necessidade de se promover a descentralização tributária, a arrecadação ainda se concentra na esfera pública central (MENDES; MIRANDA; COSIO, 2008); em outras palavras, existe uma brecha vertical resultante do fato de que os governos centrais arrecadam mais e gastam menos em relação aos governos subnacionais, daí a importância de se promoverem transferências dos entes superiores para os inferiores. A brecha vertical está relacionada à discrepância entre a centralização tributária e a descentralização da execução dos gastos e serviços públicos, maiores nas esferas subnacionais (PRADO, 2007).

Segundo esse mesmo autor, os motivos para que ocorra a centralização da arrecadação na União, e que de certa forma explicam a existência do sistema de transferências, relacionam-se: a) ao argumento normativo da eficiência econômica. Nesse sentido, a autonomia regional na definição das alíquotas tributárias poderia promover uma competição fiscal entre as unidades da federação, impactando a atividade produtiva do país. Por outro lado, a unificação de certos impostos minimizaria os efeitos perversos de uma guerra fiscal sobre o território nacional e facilitaria o cálculo por parte dos agentes econômicos; b) à necessidade de se reduzirem as desigualdades fiscais regionais, ou seja, a de se promover a equidade horizontal, tendo em vista as diferenças estruturais entre os entes subnacionais (brecha horizontal); c) à necessidade de se promoverem políticas sociais de âmbito nacional. Portanto, a existência de uma brecha vertical implica a criação de

1 Segundo Garson e Araújo (2001), a descentralização da receita promovida pela reforma tributária beneficiou, principalmente, os municípios, impactando, sobretudo, os gastos com ações sociais básicas (educação e saúde).

2 A regulamentação da repartição de receitas consta nos artigos 157 a 162 da CF. 
mecanismos de transferência vertical, de modo que o gap entre os recursos tributários obtidos na esfera subnacional e a demanda crescente por serviços públicos seja mitigado.

Mendes, Miranda e Cosio (2008) apresentam uma taxonomia das transferências intergovernamentais brasileiras de acordo com a seguinte classificação: ${ }^{3}$ a) transferências incondicionais redistributivas; b) transferências incondicionais devolutivas; c) transferências condicionais voluntárias; d) transferências condicionais obrigatórias; e) transferências ao setor produtivo privado; f) transferências diretas a indivíduos. ${ }^{4}$

As transferências incondicionais redistributivas se caracterizam pelo fato de que o agente beneficiário não se compromete a vincular o valor recebido a gastos específicos. Os critérios de partilha são definidos de acordo com fórmulas baseadas em características populacionais, de localidade do ente subnacional e da renda per capita, sendo o tipo de transferência mais utilizado quando se objetiva reduzir a brecha vertical. Entretanto, as transferências incondicionais redistributivas podem apresentar alguns problemas, sobretudo, relacionados ao risco moral, uma vez que os entes subnacionais tendem a reduzir a qualidade e o esforço fiscal local e a aumentar o gasto público (MENDES; MIRANDA; COSIO, 2008). No Brasil, pode-se mencionar o FPE e o Fundo de Participação dos Municípios (FPM).

O FPE é um instrumento de transferência legal, incondicional e redistributivo de recursos da União para os estados brasileiros e o Distrito Federal. O FPE é composto por $21,5 \%$ da arrecadação líquida do Imposto de Renda (IR) e do Imposto sobre Produtos Industrializados (IPI). A Lei Complementar $n^{\circ}$ 62/1989 determina que $85 \%$ de seus recursos devem ser distribuídos às regiões Norte, Nordeste e Centro-Oeste e $15 \%$ às regiões Sul e Sudeste. O fundo é calculado levando em consideração fatores representativos da população e a renda domiciliar per capita de cada estado. A Tabela 1 apresenta os percentuais individuais de partilha do FPE, em ordem decrescente de participação.

3 A CF prevê duas formas de transferência de recursos tributários, uma direta e outra indireta. A transferência de recursos direta se dá mediante o repasse de receitas sem qualquer tipo de intermediação entre a União e o ente subnacional, ou seja, trata-se dos impostos que são de competência exclusivamente estadual, a exemplo do Imposto sobre a Propriedade de Veículos Automotores (IPVA), do Imposto sobre a Circulação de Mercadorias e Serviços (ICMS) e do Imposto sobre Transmissão Causa Mortis e Doação (ITCMD). Por sua vez, a transferência indireta é viabilizada através de fundos de participação. Os principais fundos que intermediam a transferência União-entes subnacionais são: (i) o Fundo de Participação dos Estados e Distrito Federal (FPE) e (ii) o Fundo de Participação dos Municípios (FPM), ambos regulados pela Lei Complementar (LC) $n^{\circ}$ 62/89.

4 Para um maior aprofundamento técnico do tema, ver Mendes, Miranda e Cosio (2008). 
Tabela 1 - Percentuais individuais de distribuição do FPE

\begin{tabular}{cccc}
\hline Estado & Participação & Estado & Participação \\
\hline Bahia & 9,4 & Paraná & 2,88 \\
Ceará & 7,34 & Goiás & 2,84 \\
Maranhão & 7,22 & Rondônia & 2,82 \\
Pernambuco & 6,9 & Amazonas & 2,79 \\
Pará & 6,11 & Roraima & 2,48 \\
Paraíba & 4,79 & Rio Grande do Sul & 2,35 \\
Minas Gerais & 4,45 & Mato Grosso & 2,31 \\
Tocantins & 4,34 & Rio de Janeiro & 1,53 \\
Piauí & 4,32 & Espírito Santo & 1,5 \\
Rio Grande do Norte & 4,18 & Mato Grosso do Sul & 1,33 \\
Alagoas & 4,16 & Santa Catarina & 1,28 \\
Sergipe & 4,16 & São Paulo & 1,0 \\
Acre & 3,42 & Distrito Federal & 0,69 \\
Amapá & 3,41 & Total & 100,0 \\
\hline
\end{tabular}

Fonte: Elaboração própria a partir de Brasil (2016).

\subsection{Uma Breve Nota sobre o Índice de Dependência dos Estados Brasileiros (ldep)}

É bem sabido que os níveis inferiores de governo arrecadam menos recursos do que gastam, tendo em vista a base tributária que lhes é atribuída, o que, por sua vez, os restringe de obter recursos tributários de maneira autônoma. Esse condicionamento acaba tornando os governos subnacionais dependentes das transferências da União de modo que se devem criar mecanismos que reduzam a brecha vertical entre a União e os entes federativos menores. De acordo com Prado (2007), uma maneira de se calcular a brecha vertical é por meio da razão entre os recursos próprios obtidos pelo governo subnacional e os recursos a ele transferidos pela União. ${ }^{5}$ Nesse sentido, o Idep foi construído a partir do quociente entre o FPE e a RCL de cada estado.

O índice demonstra o quanto cada ente federativo depende das transferências da União para executar os seus gastos. É importante destacar que a RCL é o indicador mais importante do texto da LRF. Seu cálculo serve de parâmetro para os limites (ou restrições) com os quais os estados se defrontam ao planejar os seus gastos com pessoal, dívida pública, serviços de terceiros, operações de crédito e garantias concedidas (BANCO NACIONAL DE DESENVOLVIMENTO ECONÔMI-

5 Prado (2007) cita, ainda, a razão entre recursos próprios e gastos totais. 
CO E SOCIAL, 2016). Desse modo, quando se calcula a relação entre o FPE e a $\mathrm{RCL}$, tem-se um indicador do quanto a receita estadual é dependente das transferências da União. Nesse sentido, quanto mais próximo da unidade estiver o indicador, maior será o grau de dependência do ente subnacional em relação às transferências da União. O Gráfico 1 apresenta os valores médios do Idep calculados, no período de 2000 a 2010, para cada unidade da federação mais o Distrito Federal.

Gráfico 1 - Idep médio por estado (2000-2011)

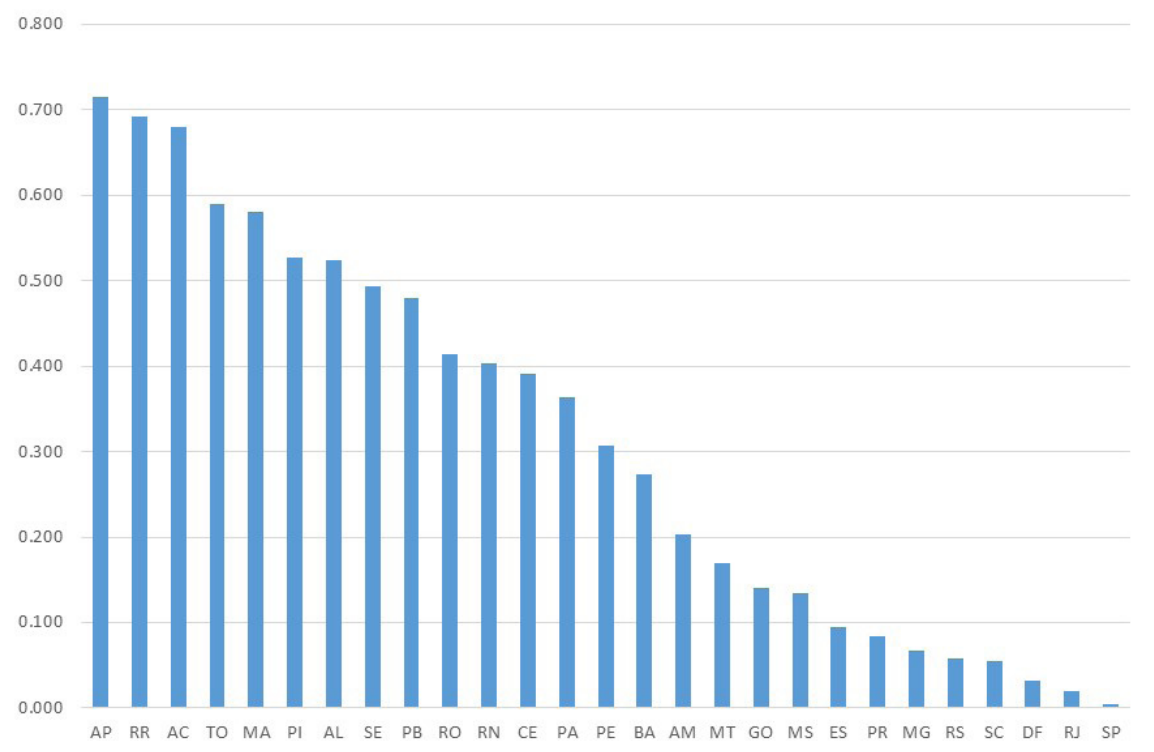

Fonte: Elaboração própria.

No Gráfico 1, os picos representam os estados com o maior Idep, os estados do Amapá (0.715), Roraima (0.693), Acre (0.680), Tocantins (0.589), Maranhão (0.580) e Piauí (0.527), sendo alguns os estados com maiores percentuais de distribuição do FPE (ver Tabela 1), a exemplo dos estados do Maranhão, Tocantins e Piauí, que ocupam a terceira, oitava e nona posições, respectivamente. Por outro lado, quanto menor o retângulo, menor o grau de dependência da unidade da federação em relação ao FPE. Nesse caso, podem-se mencionar os estados de São Paulo (0.05), Rio de Janeiro (0.02), Distrito Federal (0.033), Santa Catarina (0.055) e Rio Grande do Sul (0.057), portanto, os estados com menores percentuais de distribuição do FPE. 


\subsection{O Modelo de Regressão com Efeito Threshold Simples}

A abordagem clássica de efeitos fixos permite analisar a heterogeneidade nos interceptos, sem, entretanto, levar em consideração possíveis diferenças capturadas nas inclinações dos modelos de regressão (WANG, 2014). Nesse particular, o uso de modelos com efeito threshold permite avaliar quebras estruturais no relacionamento entre as variáveis tal qual a formação de clusters, ou seja, duas ou mais classes de observações podem ser obtidas a partir do valor de uma variável observável. Para a estimação empírica do modelo, o painel deve ser balanceado $\left\{\mathrm{y}_{\mathrm{it},}, \mathrm{q}_{\mathrm{it}}, \mathrm{x}_{\mathrm{it}}: 1 \leq \mathrm{i} \leq \mathrm{n}, 1 \leq \mathrm{t} \leq \mathrm{T}\right\}$ e de acordo com a seguinte equação estrutural (HANSEN, 1999):

$$
\mathrm{y}_{\mathrm{it}}=\mu+\beta_{1}{ }^{\prime} \mathrm{x}_{\mathrm{it}} \mathrm{I}\left(\mathrm{q}_{\mathrm{it}} \leq \gamma\right)+\beta_{2}{ }^{\prime} \mathrm{x}_{\mathrm{it}} \mathrm{I}\left(\mathrm{q}_{\mathrm{it}}>\gamma\right)+\mu_{\mathrm{i}}+\epsilon_{\mathrm{it}}
$$

em que I( $\cdot$ ) denota uma função característica. A equação 1 pode ser reescrita na seguinte forma compacta:

$$
y_{i t}= \begin{cases}\mu_{i}+\beta_{1}^{\prime} x_{i t}+\varepsilon_{i t}, & q_{i t} \leq \gamma \\ \mu_{i}+\beta_{2}^{\prime} x_{i t}+\varepsilon_{i t}, & q_{i t}>\gamma\end{cases}
$$

Seguindo a taxonomia padrão da literatura de dados em painel, os subscritos it indexam o indivíduo i no tempo $t$. A variável dependente $\left(y_{\mathrm{it}}\right)$ e a variável de threshold $\left(q_{\mathrm{it}}\right)$ são escalares, o regressor $\left(x_{\mathrm{it}}\right)$ é um vetor de tamanho $k, \epsilon_{\mathrm{it}}$ é o termo de erro i.i.d., com média zero e variância $\sigma^{2}$ e $\mu_{i}$ é o efeito fixo individual. A equação 2 demonstra que as observações amostrais poderão ser divididas em dois regimes distintos dependendo se o valor da variável $q_{i t}$ estiver acima ou abaixo do parâmetro de threshold ( $\gamma$ ) (HANSEN, 1999). Reescrevendo a equação 2, chega-se à seguinte equação estrutural:

$$
\mathrm{y}_{\mathrm{it}}=\mu_{\mathrm{i}}+\beta^{\prime} \mathrm{x}_{\mathrm{it}}(\gamma)+\mathrm{e}_{\mathrm{it}}
$$

Dado o valor do parâmetro $\gamma$, o estimador de $\beta$ será:

$$
\hat{\beta}(\gamma)=\left\{X^{*}(\gamma)^{\prime} X^{*}(\gamma)\right\}^{-1}\left\{X^{*}(\gamma)^{\prime} y^{*}\right\}
$$

É importante destacar que os parâmetros $X^{*}$ e $y^{*}$ representam as observações transformadas pela média, visando à exclusão do efeito fixo. A estimação dos parâmetros do modelo, incluindo o parâmetro $\gamma$, é feita por meio do método dos mínimos quadrados ordinários (MQO). A estimação do parâmetro $\gamma$, em particu- 
lar, exige que se estabeleça um intervalo $(\underline{\gamma}, \bar{\gamma})$, que são os quantis de $q_{i t}$, dentro do qual procura-se o valor do parâmetro $\gamma$. Esse intervalo é estabelecido dentro do subconjunto da variável de threshold, e o estimador do parâmetro $\gamma$ será aquele que minimiza a soma dos quadrados dos resíduos (SQR). Caso o parâmetro $\gamma$ seja conhecido, o modelo será um modelo linear convencional, sem efeito threshold. Caso contrário, o estimador de $\gamma$ será um estimador ingênuo, violando a hipótese de normalidade dos resíduos (WANG, 2014). Para contornar esse problema, Hansen (1999) demonstra que é possível identificar consistentemente o parâmetro $\gamma$ por meio da estimação de intervalos de confiança (bootstrap) utilizando-se o método de máxima verossimilhança, empregando-se a estatística LR.

Desse modo, a hipótese nula a ser testada será se os dois modelos de regressão apresentam a mesma inclinação (o threshold não é identificado e o modelo é linear), ou seja, testa-se $H_{0}=\beta_{1}=\beta_{2} \mathrm{X} H_{a}=\beta_{1} \neq \beta_{2}$. Se a hipótese da linearidade não é aceita, deve-se proceder à estimação de um modelo com dois efeitos thresholds, sob a hipótese nula de que o modelo com apenas um threshold é adequado. Se a hipótese nula não é aceita, deve-se estimar um modelo com três thresholds e, assim, sucessivamente. $\mathrm{O}$ algoritmo termina quando a hipótese nula não pode mais ser rejeitada (WANG, 2014).

\section{Análise dos Resultados}

Para se analisar o efeito das transferências da União sobre o crescimento econômico dos estados e o Distrito Federal, utiliza-se um painel de efeitos fixos com efeito threshold, no período de 2000 a 2011 . Esse período se justifica pelo fato de não dispor de dados para a RCL antes do ano 2000, ano em que é implementada a lei orçamentária no Brasil com a introdução do conceito RCL. Serão estimados dois modelos, que diferem entre si apenas na variável threshold utilizada. O primeiro modelo, o modelo principal, utiliza como variável threshold o Idep, enquanto o segundo utiliza a razão ICMS/RCL.

Nesse sentido, adota-se a hipótese de que, uma vez capturada a existência de diferentes regimes no modelo Idep - o que produz diferentes dinâmicas entre a taxa de crescimento econômico e a variável dependente do regime, o IGP -, espera-se a mesma dinâmica ao introduzir-se a variável threshold ICMS/RCL, pois os estados mais dependentes das transferências da União são justamente aqueles que apresentam menor autonomia fiscal, ou seja, menor razão ICMS/RCL.

Tendo-se por referência o modelo de Devarajan, Swarrop e Zou (1996), a variável dependente deverá capturar o crescimento econômico de longo prazo das unidades de análise. Por essa razão, usa-se a taxa de crescimento do PIB real per capita um período à frente. Esse artifício possibilita minimizar uma possível fonte de endogeneidade do modelo, uma vez que o crescimento econômico pode 
estar influenciando a razão gasto total versus PIB (G/Y). Os dados referentes ao PIB real per capita são publicados pelo IBGE e foram extraídos do banco de dados disponibilizado pelo Instituto de Pesquisa Econômica Aplicada (Ipea) (IPEADATA, 2016).

Um pré-requisito para a implementação empírica do modelo de Hansen (1999) é que o painel seja balanceado $\left\{y_{i t}, q_{i t}, x_{i t}: 1 \leq i \leq n, 1 \leq t \leq T\right\}$. A construção do modelo de Devarajan, Swarrop e Zou (1996) leva em conta essa restrição, uma vez que algumas observações das variáveis de gastos por função, constantes na execução orçamentária, são faltantes. Desse modo, foram selecionadas as seguintes variáveis independentes: a) razão gasto/PIB (rgpib); b) razão educação/gasto total (redugt); c) razão indústria, comércio e serviços/gasto total (ricsgt); d) razão assistência e previdência/gasto total (rassprevgt); e) razão saúde e saneamento/ gasto total (rsausangt); f) taxa de desemprego (txdesemp); e g) dummy da LRF. Como variável dependente do regime de threshold, foi selecionada a razão IGP (igp), e, como variável threshold, o Idep. A taxa de desemprego foi extraída do banco de dados do Departamento de Informática do SUS (DATASUS, 2016).

O Gráfico 2 apresenta a taxa de crescimento econômico em relação ao Idep. A visualização gráfica, apesar de simples, pode fornecer algum insight em relação ao tipo de relacionamento esperado entre as variáveis de estudo. Foram ajustados dois tipos de modelos aos dados, um quadrático e outro não paramétrico (ou lowess). À primeira vista, pode-se esperar um relacionamento não linear entre a taxa de crescimento econômico e a variável Idep, como sugerem os dois modelos ajustados. É notável que existe uma associação negativa entre as duas variáveis até certo limiar, a partir do qual a associação passa a ser positiva. 
Gráfico 2 - logPIBpc versus Idep

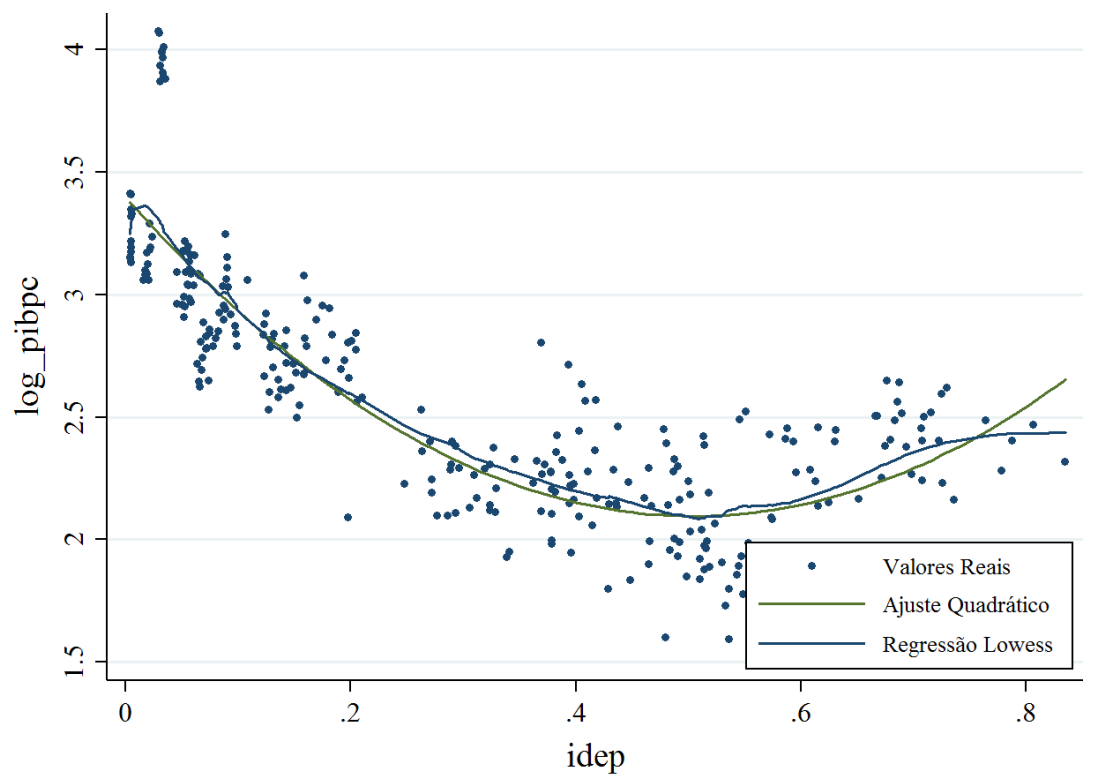

Fonte: Elaboração própria.

Além da análise gráfica, foi feita uma análise preliminar de cluster, com o objetivo de verificar como os estados brasileiros se agrupam naturalmente de acordo com as características selecionadas. A análise de cluster é conveniente uma vez que não são feitas hipóteses a priori acerca da estrutura do agrupamento, deixando os dados falarem por si. Para a formação do cluster, foi adotado o método de agrupamento hierárquico, que consiste, primeiramente, em formar tantos grupos quanto o número de observações da matriz de dados. Eventualmente, relaxa-se o critério de similaridade de modo que os subgrupos se fundam em um só. As observações foram agrupadas de acordo com a distância euclidiana usando-se o método de ligação simples (JOHNSON; WICHERN, 2007; CARVALHO, 2005).

O resultado da análise de cluster sugere a seguinte estrutura de agrupamento: ${ }^{6}$ primeiro grupo formado pelo estado de São Paulo; segundo grupo formado pelos estados do Rio de Janeiro e Santa Catarina; terceiro grupo formado pelo Distrito Federal; quarto grupo formado pelos estados do Rio Grande do Sul e Espírito Santo; e quinto grupo formado pelos estados de Minas Gerais, Paraná, Mato Grosso do Sul, Goiás, Mato Grosso, Amazonas, Bahia, Pernambuco, Pará, Ceará, Rio Grande do Norte, Rondônia, Paraíba, Sergipe, Alagoas, Piauí, Maranhão, Tocantins, Acre, Roraima e Amapá.

6 O dendrograma encontra-se no Apêndice A. 
Aparentemente, a estrutura de agrupamento é formada a partir dos estados com maior PIB per capita, maior razão gasto/PIB e menor grau de dependência em relação às transferências da União (Idep) em direção aos estados com menor PIB per capita, menor razão gasto público/PIB e com maior grau de dependência em relação às transferências da União (Idep). O resultado da análise de cluster demonstra apenas que os estados das regiões norte, nordeste e centro-oeste tendem a se agrupar, naturalmente, em torno de um vetor de características sem, entretanto, informar qual o limiar dessa discriminação. O modelo de regressão com efeito threshold vem, justamente, preencher essa lacuna, pois pressupõe uma análise ceteris paribus, que captura o efeito de uma variável sobre o comportamento de outra.

Utilizando-se a metodologia proposta por Hansen (1999), o modelo econométrico a ser estimado será:

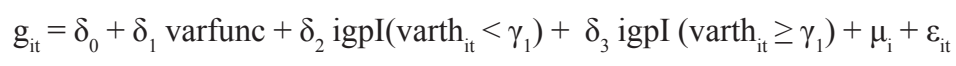

em que:

$\mathrm{g}=$ taxa de crescimento econômico;

varfunc $=$ vetor de variáveis de controle, sendo: a) rgpib $=\log$ da razão gasto total/PIB; b) rgpibquad = termo quadrático da razão gasto total/PIB; c) redugt $=\log$ da razão gasto em educação/gasto total; d) ricsgt = log da razão gasto em indústria, comércio e serviço/gasto total; e) rassprevgt = log da razão gasto em assistência e previdência/gasto total; f) rsausangt $=\log$ da razão saúde e saneamento/gasto total; g) lrf = dummy da LRF; h) txdesemp = taxa de desemprego;

igp = razão investimento/gasto com pessoal (trata-se da variável dependente do regime);

varth $=$ valor do Idep, no primeiro momento, e valor da razão ICMS/RCL, no segundo modelo.

$\varepsilon_{i t}=$ termo de erro.

A variável Idep foi escolhida como a variável threshold do primeiro experimento e a variável ICMS/RCL, a variável threshold do segundo. O teste do multiplicador de Lagrange é utilizado para se avaliar a hipótese nula $\left(H_{0}\right)$ de ausência do efeito threshold (modelo linear) contra a hipótese alternativa $\left(H_{a}\right)$ de um modelo com apenas um threshold. Uma vez sendo rejeitada a $H_{0}$, deve-se executar novamente o teste LM testando-se a $H_{0}$ de um modelo com apenas um threshold contra a $H_{0}$ de um modelo com dois thresholds, e, assim, sucessivamente até a não rejeição da hipótese nula. O p-valor é calculado por meio da técnica de bootstrap, e o teste de Lagrange é programado para a correção de eventuais problemas de heterocedasticidade. 
A Tabela 2 apresenta os resultados dos modelos. A primeira parte da tabela contém os valores dos thresholds com os respectivos intervalos de confiança. A segunda parte, por sua vez, apresenta os testes padrão da modelagem, a saber, a soma dos quadrados dos resíduos (SQR), o erro quadrático médio (EQM), a estatística $\mathrm{F}$ (F-estat), o p-valor da estatística $\mathrm{F}$ e o valor crítico a 1\%. Por fim, a terceira parte da tabela apresenta os resultados dos modelos de regressão.

Tabela 2 - Resultado do modelo threshold para as variáveis Idep e ICMSRCL

\begin{tabular}{|c|c|c|c|c|c|c|c|c|c|}
\hline & & \multicolumn{2}{|c|}{ Threshold } & \multicolumn{2}{|c|}{ Menor } & Maior & & & \\
\hline Modelo IDE & & \multicolumn{2}{|c|}{0.4868} & \multicolumn{2}{|c|}{0.4733} & 0.4908 & & & \\
\hline Modelo ICMSF & & \multicolumn{2}{|c|}{0.3822} & \multicolumn{2}{|c|}{0.3487} & 0.3915 & & & \\
\hline \multicolumn{2}{|c|}{ Threshold Simples } & \multicolumn{2}{|c|}{ SQR } & \multicolumn{2}{|c|}{ EQM } & Festat & Prob & \multicolumn{2}{|l|}{ Crítico (\%) } \\
\hline \multicolumn{2}{|c|}{ Modelo IDEP } & \multicolumn{2}{|c|}{1.4767} & \multicolumn{2}{|c|}{0.0052} & 40.44 & 0.0033 & \multicolumn{2}{|l|}{$33.96(1 \%)$} \\
\hline \multicolumn{2}{|c|}{ Modelo ICMSRCL } & \multicolumn{2}{|c|}{1.5741} & \multicolumn{2}{|c|}{0.0055} & 20.25 & 0.0300 & \multicolumn{2}{|l|}{$25.54(1 \%)$} \\
\hline \multicolumn{2}{|l|}{ logpibpc } & \multicolumn{2}{|c|}{$\begin{array}{c}\text { Coeficientes } \\
\text { Modelo IDEP }\end{array}$} & & & \multicolumn{4}{|c|}{$\begin{array}{c}\text { Coeficientes } \\
\text { Modelo ICMSRCL }\end{array}$} \\
\hline rgpib & $\begin{array}{l}0.6924^{*} \\
(0.3177)\end{array}$ & 2000 & $\begin{array}{c}0.0024 \\
(0.0225)\end{array}$ & 2010 & omitido & $\begin{array}{l}0.7517^{*} \\
(0.331)\end{array}$ & 2000 & $\begin{array}{ll}-0.016 \quad 2010 \\
(0.0231)\end{array}$ & omitido \\
\hline redugt & $\begin{array}{c}-0.0729 * \\
(0.0313)\end{array}$ & 2001 & $\begin{array}{l}-0.0121 \\
(0.0223)\end{array}$ & 2011 & $\begin{array}{l}-0.0131 \\
(0.0226)\end{array}$ & $\begin{array}{c}-0.0726^{*} \\
(0.0324)\end{array}$ & 2001 & $\begin{array}{ll}-0.0183 & 2011 \\
(0.0231) & \end{array}$ & $\begin{array}{l}-0.0166 \\
(0.0233)\end{array}$ \\
\hline ricsgt & $\begin{array}{l}-0.0004 \\
(0.0068)\end{array}$ & 2002 & $\begin{array}{c}0.0142 \\
(0.0226)\end{array}$ & & & $\begin{array}{c}-0.001 \\
(0.0071)\end{array}$ & 2002 & $\begin{array}{c}0.0019 \\
(0.0233)\end{array}$ & \\
\hline rassprevgt & $\begin{array}{c}0.023^{*} \\
(0.0124)\end{array}$ & 2003 & $\begin{array}{l}0.0204 \\
(0.023)\end{array}$ & & & $\begin{array}{c}0.0197 \\
(0.0128)\end{array}$ & 2003 & $\begin{array}{c}0.0104 \\
(0.0237)\end{array}$ & \\
\hline rsausangt & $\begin{array}{l}0.1334^{*} \\
(0.0212)\end{array}$ & 2004 & $\begin{array}{c}0.0102 \\
(0.0227)\end{array}$ & & & $\begin{array}{l}0.1385^{*} \\
(0.0218)\end{array}$ & 2004 & $\begin{array}{c}0.0068 \\
(0.0234)\end{array}$ & \\
\hline txdesemp & $\begin{array}{l}-0.055^{*} \\
(0.0255)\end{array}$ & 2005 & $\begin{array}{l}-0.0049 \\
(0.0226)\end{array}$ & & & $\begin{array}{l}-0.0566^{*} \\
(0.0263)\end{array}$ & 2005 & $\begin{array}{l}-0.0108 \\
(0.0235)\end{array}$ & \\
\hline $\operatorname{lrf}$ & $\begin{array}{c}0.0923^{*} \\
(0.017)\end{array}$ & 2006 & $\begin{array}{c}0.0051 \\
(0.0222)\end{array}$ & & & $\begin{array}{l}0.0873^{*} \\
(0.0175)\end{array}$ & 2006 & $\begin{array}{l}-0.0017 \\
(0.023)\end{array}$ & \\
\hline regime 1 & $\begin{array}{l}0.2453^{*} \\
(0.0529)\end{array}$ & 2007 & $\begin{array}{l}0.0047 \\
(0.225)\end{array}$ & & & $\begin{array}{c}-0.0998^{* *} \\
(0.0608)\end{array}$ & 2007 & $\begin{array}{c}0.0051 \\
(0.0233)\end{array}$ & \\
\hline regime 2 & $\begin{array}{r}-0.1153^{*} \\
(0.0539)\end{array}$ & 2008 & $\begin{array}{c}0.01 \\
(0.0225)\end{array}$ & & & $\begin{array}{l}0.1826^{*} \\
(0.0527)\end{array}$ & 2008 & $\begin{array}{c}0.0086 \\
(0.0232)\end{array}$ & \\
\hline constante & $\begin{array}{l}2.3815^{*} \\
(0.1228) \\
\end{array}$ & 2009 & $\begin{array}{c}0.0081 \\
(0.0225) \\
\end{array}$ & & & $\begin{array}{l}2.3839^{*} \\
(0.1269) \\
\end{array}$ & 2009 & $\begin{array}{r}0.0124 \\
(0.0232) \\
\end{array}$ & \\
\hline N. Obs. & 297 & & & & & 297 & & & \\
\hline $\begin{array}{c}\text { Festat } \\
\text { R2 }\end{array}$ & 16.87 & & & & & 15.06 & & & \\
\hline within & 0.5744 & & & & & 0.5464 & & & \\
\hline between & 0.0583 & & & & & 0.3114 & & & \\
\hline overall & 0.0001 & & & & & 0.0243 & & & \\
\hline
\end{tabular}

Fonte: Elaboração própria.

Nota: * variáveis significativas até 5\%; ** variáveis significativas até 10\%; nulo: variáveis não significativas; erros padrões entre parênteses.

Os resultados econométricos apontam algumas relações interessantes. $O R^{2}$ within apresentou valores mais elevados, tanto para o modelo Idep (0.5744) quanto para o modelo ICMS/RCL (0.5464), indicando que a variação no tempo é maior do que a variação entre os estados. Em termos de significância dos parâmetros, à exceção dos gastos em assistência e previdência, as demais rubricas apresentaram parâmetros significativos e com valores bem próximos, para ambos os modelos. 
Utilizando-se a nomenclatura de gastos produtivos e improdutivos, pode-se afirmar que, possivelmente, os gastos públicos totais são produtivos, isto é, impactam positivamente o crescimento econômico dos estados mais o Distrito Federal. Um aumento de $1 \%$ na razão gasto total/PIB (rgpib) está associado a um aumento de $0.69 \%$ (modelo Idep) e $0.76 \%$ (modelo ICMSRCL) na taxa de crescimento econômico dos entes federativos. Do mesmo modo, os gastos em saúde e saneamento (rsausangt) também se mostraram produtivos. Um aumento de 1\% nessa razão está associado a um aumento de 0.13\% (modelo Idep) e 0.14\% (modelo ICMSRCL) na taxa de crescimento econômico estadual.

Por outro lado, o gasto em educação pública (redugt) apresentou parâmetro negativo, o que indica que, possivelmente, esse gasto tem sido improdutivo para o crescimento econômico. Em relação aos gastos em educação pública, um aumento de $1 \%$ nessa razão está associado a um decrescimento do PIB na ordem de $0.073 \%$ em ambos os modelos. Cabe destacar o efeito positivo da LRF sobre o crescimento, indicando que a imposição de regras tem sido benéfica ao crescimento econômico dos estados.?

Em relação à estimação dos parâmetros das variáveis Idep e ICMSRCL, foi rodado, em um primeiro estágio, um modelo com apenas um efeito threshold, testando-se a $H_{0}$ de um modelo linear contra a $H_{a}$ de um modelo com um efeito threshold. Tendo-se em vista que a $H_{0}$ foi rejeitada com segurança, o algoritmo sugere que seja rodado outro modelo, testando-se a $H_{0}$ de efeito threshold simples contra a $H_{a}$ de um modelo com dois efeitos threshold. Nessa etapa, a $H_{0}$ não pôde ser rejeitada, endossando a hipótese de um modelo com apenas um threshold.

Os resultados do modelo Idep apontam um duplo agrupamento: o primeiro grupo, formado pelos estados com Idep $<0.4868$, e o segundo grupo, pelos estados com Idep $\geq 0.4868$. A Figura 1 ilustra a formação desses agrupamentos. Os estados pertencentes ao primeiro grupo foram São Paulo, Rio de Janeiro, Distrito Federal, Santa Catarina, Rio Grande do Sul, Minas Gerais, Paraná, Espírito Santo, Mato Grosso do Sul, Goiás, Mato Grosso, Amazonas, Bahia, Pernambuco, Pará, Ceará, Rio Grande do Norte e Rondônia. O segundo grupo foi formado pelos estados da Paraíba, Sergipe, Alagoas, Piauí, Maranhão, Tocantins, Acre, Roraima e Amapá.

$7 \quad$ Não é mérito do presente ensaio julgar as possíveis causas da produtividade ou improdutividade dos gastos públicos estaduais, senão o efeito das transferências fiscais sobre o crescimento econômico. 
Figura 1 - Mapa do modelo Idep

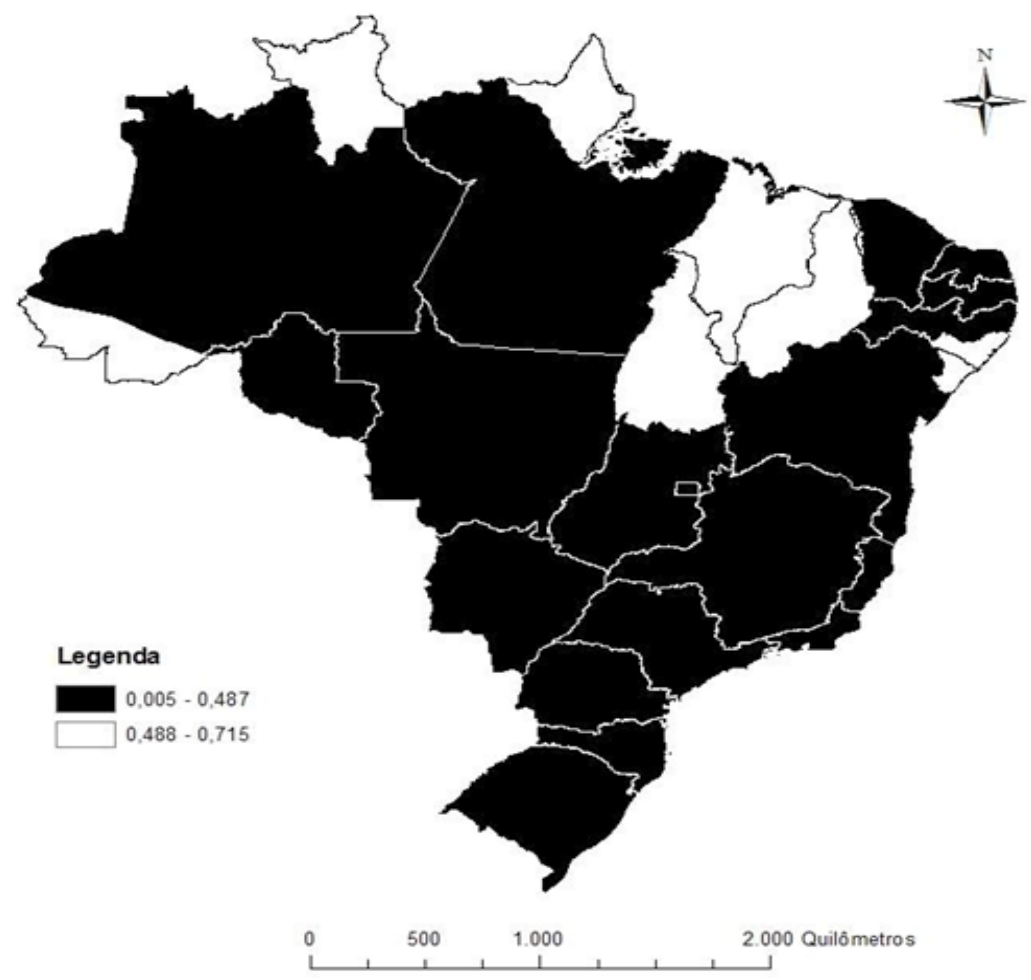

Fonte: Elaboração própria.

Uma vez que a variável IGP foi definida como a variável dependente do regime de threshold, a análise dos resultados deve contar com ela. O primeiro modelo (Idep) vai capturar o relacionamento entre o IGP e a taxa de crescimento econômico dos estados, tendo em vista o efeito do Idep sobre essa dinâmica, enquanto que o segundo modelo (modelo ICMSRCL) vai capturar o relacionamento entre aquelas variáveis, porém levando em consideração o efeito da razão ICMS/RCL.

Nesse sentido, para os estados pertencentes ao segundo grupo, que são os estados mais dependentes das transferências da União, ${ }^{8}$ existe uma associação negativa entre IGP e taxa de crescimento econômico. Um aumento de 1\% na razão IGP promove um decrescimento do PIB na ordem de $0.11 \%$. Esse resultado pode ser visualizado na Tabela 2 (regime 2). Por outro lado, para os estados pertencentes ao primeiro grupo, com menor grau de dependência tributária, a dinâmica

8 São os estados do Amapá (0.715), Roraima (0.693), Acre (0.680), Tocantins (0.589), Maranhão (0.58), Piauí (0.527), Alagoas (0.525), Sergipe (0.494) e Paraíba (0.479). Esses estados apresentam um maior grau de dependência em relação às transferências da União. 
entre a razão IGP e a taxa de crescimento é outra: um aumento de 1\% na razão IGP está associado a um aumento de $0.24 \%$ no crescimento econômico desses estados. Esse resultado pode ser visualizado na Tabela 2 (regime 1).

Essa dinâmica é corroborada ao incluir-se a variável ICMSRCL como variável threshold. De acordo com a Tabela 2, o valor do threshold para essa variável foi de 0.3822 , o que sugere a seguinte estrutura de agrupamento: o primeiro grupo, formado pelos estados com menor autonomia fiscal (> 0.3822), Paraíba, Piauí, Tocantins, Acre, Roraima e Amapá (ou seja, à exceção dos estados do Maranhão, Sergipe e Alagoas, trata-se do segundo grupo do modelo Idep); e o segundo grupo formado pelos estados com maior autonomia fiscal (> 0.3822), Maranhão, Sergipe e Alagoas. A Figura 2 sintetiza essa estrutura de agrupamento.

Figura 2 - Mapa do modelo ICMSRCL

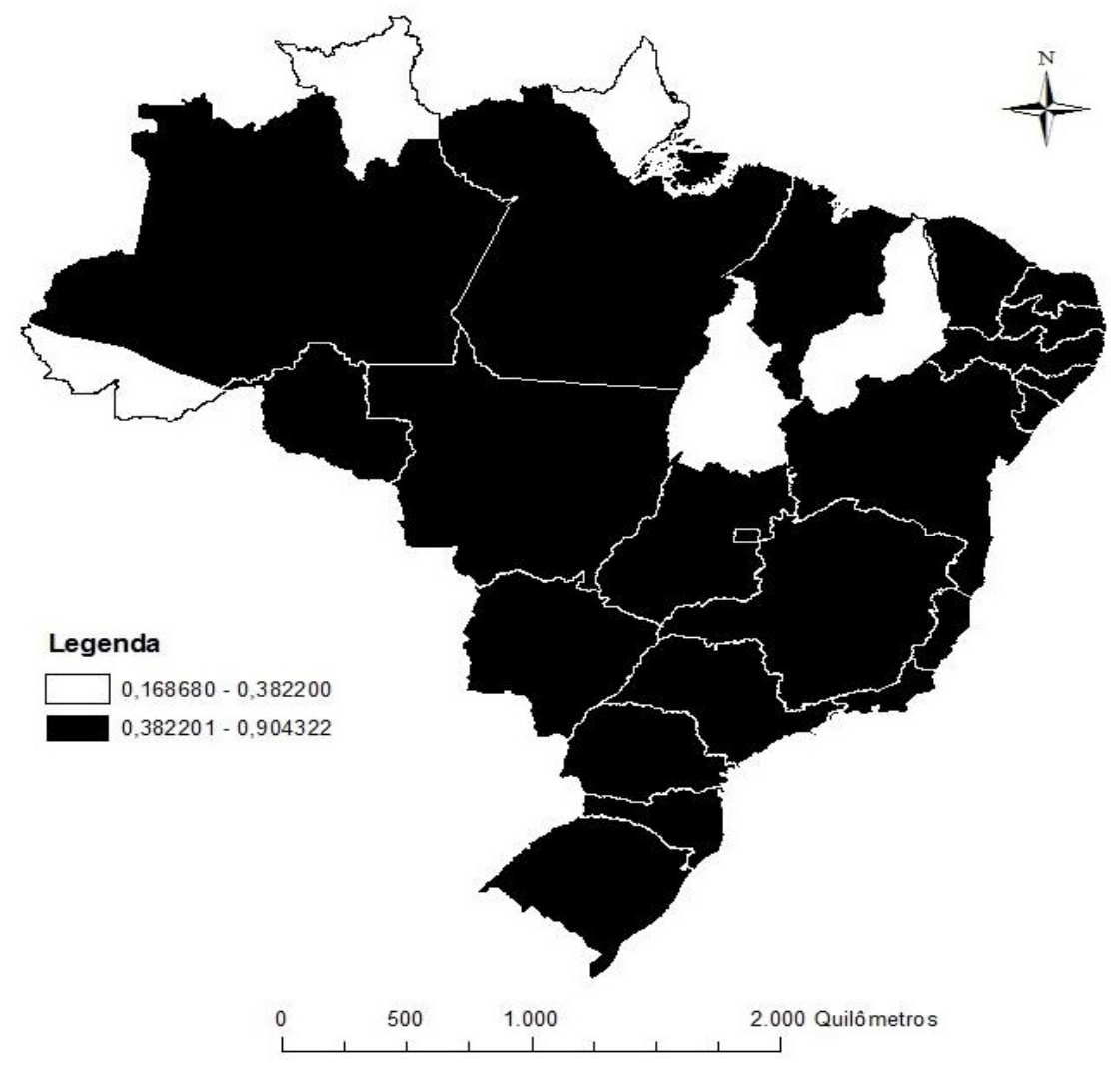

Fonte: Elaboração própria.

Portanto, pode-se inferir que os estados com menor autonomia fiscal e, consequentemente, maior dependência em relação às transferências da União são 
aqueles em que a associação entre IGP e taxa de crescimento econômico é negativa. Em outras palavras, um aumento de 1\% na razão IGP está associado a uma redução de $0.1 \%$ na taxa de crescimento econômico dos estados pertencentes ao primeiro grupo (regime 1). Por outro lado, um aumento de $1 \%$ nessa rubrica promove um aumento de $0.18 \%$ na taxa de crescimento dos estados com maior autonomia fiscal (regime 2).

\section{Considerações Finais}

O presente artigo buscou analisar o impacto da brecha vertical, medida a partir de um índice de dependência construída a partir da razão entre o FPE e a RCL (Idep) sobre o desempenho econômico dos estados brasileiros mais o Distrito Federal, utilizando o modelo de efeitos fixos com threshold de Hansen (1999) para o período de 2000 a 2011. O Idep acabou servindo ao objetivo de avaliar como os entes federativos se agrupam em termos de dependência em relação às transferências da União.

Para se assegurar que o resultado não foi apenas uma coincidência econométrica, construiu-se um modelo econométrico alternativo, em que a razão ICMS/ RCL passou a desempenhar o papel de variável de threshold. A razão por trás desse experimento esteve relacionada ao fato de que, uma vez o modelo Idep agrupando as observações de acordo com o grau de dependência que apresentam, um resultado oposto deveria ser encontrado com a variável ICMSRCL, uma vez que os estados com maior dependência de recursos tributários são justamente aqueles que apresentam uma menor autonomia fiscal.

De fato, os resultados corroboraram essa hipótese, mostrando que, no modelo Idep, Paraíba, Sergipe, Alagoas, Piauí, Maranhão, Tocantins, Acre, Roraima e Amapá, e no modelo ICMSRCL, à exceção dos estados do Maranhão, Sergipe e Alagoas, por apresentarem um maior grau de dependência em relação às transferências da União e, consequentemente, uma menor autonomia fiscal, se agruparam de acordo com as características tributárias. Entretanto, esse agrupamento acabou sinalizando a existência de uma relação perversa entre a razão IGP e a taxa de crescimento econômico, em que, para um aumento de 1\% na razão I/GP, a taxa de crescimento econômico desses entes subnacionais decrescia, em média, 0.11\%, no modelo IDEP, e $0.1 \%$, no modelo ICMSRCL.

Além disso, o modelo econométrico de base à análise threshold foi inspirado no modelo matemático de Devarajan, Swarrop e Zou (1996), para o qual foram encontrados os seguintes resultados, seguindo-se a nomenclatura de gastos produtivos e improdutivos: a) os gastos públicos totais e os gastos em assistência e previdência mostrando-se produtivos; e b) os gastos em educação pública e indústria, comércio e serviços mostrando-se improdutivos. Um resultado que chama 
a atenção é a dummy da LRF, que apresentou parâmetro positivo e significativo. Esse resultado pode significar que a introdução de regras fiscais vem sendo benéfica para os entes federativos.

A literatura aponta algumas possíveis causas para esse fenômeno no âmbito da discussão acerca da qualidade do gasto público. Regimes de transferências fiscais podem alterar a estrutura de incentivos com que os indivíduos se defrontam, distorcendo decisões econômicas importantes. De acordo com Barro (1999), quanto maior o valor da renda distribuída, maior será o grau de distorção produzido, consubstanciado em baixos níveis de investimento e, consequentemente, baixas taxas de crescimento econômico. Além disso, o resultado encontrado pode estar indicando que os gastos públicos vêm sendo executados com baixa qualidade, possivelmente em função de uma distorção de incentivos frequente em regimes de equalização fiscal vertical ou paternal, a exemplo do caso brasileiro.

\section{Referências}

BANCO NACIONAL DE DESENVOLVIMENTO ECONÔMICO E SOCIAL. Comentários à lei de responsabilidade fiscal. Brasília, 2001. Disponível em: <https://web.bndes.gov. br/bib/jspui/bitstream/1408/3461/1/Coment\%c3\%a1 rios\%20\%c3\%a0\%20Lei\%20de\%20 Responsabilidade\%20Fiscal_Cadernos\%20Ibam_1_P.pdf > . Acesso em: 17 fev 2015.

BARBOSA, H. F. (Org.). Federalismo fiscal, eficiência e equidade: uma proposta de reforma tributária. Brasília: Fundação Getúlio Vargas, 1998.

BARRETI, C.; HUBER, B.; LICHTBLAU, K. A tax on tax revenue: the incentive effects of equalizing transfers: evidence from Germany. International Tax and Public Finance, v. 9, n. 9, p. 634-649, 2002.

BARRO, R. J. Inequality, growth and investment. Massachusetts: National Bureau of Economic Research, 1999. (NBER Working Paper, n. 7038).

BLOCHLIGER, H.; CHARBIT, C. Fiscal equalization. OECD Economic Studies, n. 44, p. 1-22, 2008.

BOADWAY, R. The theory and practice of equalization. CESifo Economic Studies, v. 50, p. 211-254, 2004.

BOADWAY, R.; FLATTERS, F. Efficiency and equalization payments in a federal system of government: a synthesis and extension of recent results. Canadian Journal of Economics, v. 50, n. 1, p. 211-254, 2004

BOADWAY, R.; HAYASHI, M. An evaluation of the stabilization properties of equalization in Canada. Canadian Public Policy, v. 30, n. 1, p. 91-109, 2004.

BRASIL. Constituição da República Federativa do Brasil de 1988. Brasília, 1988. Disponível em: <http://www.planalto.gov.br/ccivil_03/Constituicao/Constituicao.htm>. Acesso em: 05 jun. 2016. 
. Ministério da Saúde. Departamento de Informática do SUS. Informações de saúde (TABNET). Disponível em: <http://www2.datasus.gov.br/DATASUS/index.php?area=02>. Acesso em: 17 jan. 2015.

. Secretaria do Tesouro Nacional. Disponível em: < http://www.tesouro.fazenda.gov. br/>. Acesso em: 17 jan. 2015.

BUCHANAN, J. M. Federal grants and resource allocation. Journal of Political Economy, v. 60, p. 208-217, 1952.

. Federalism and fiscal equity. American Economic Review, v. 40, p. 583-599, 1950.

BUCHANAN, J. M.; GOETZ, J. C. Efficiency limits of fiscal mobility: an assessment of the tiebout model. Journal of Public Economics, v. 1, n. 1, p. 25-43, 1972.

CARVALHO, L. A. V. Datamining: a mineração de dados no marketing, medicina, economia, engenharia e administração. Rio de Janeiro: Ciência Moderna, 2005.

CHECHERITA, C.; NICKEL, C.; ROTHER, P. The role of fiscal transfers for regional economic convergence in Europe. Frankfurt: European Central Bank, 2009. (European Central Bank Working Paper, n. 1029).

CONTI, M. J. (Org.). Federalismo fiscal. São Paulo: Manole, 2004.

DAHLBY, B. The incentive effects of fiscal equalization grants. Atlantic Institute for Market Studies, artigo 4, 2002.

DEVARAJAN, S.; SWARROP, V.; ZOU, H. The composition of public expenditure and economic growth. Journal of Monetary Economics, v. 37, n. 2, p. 313-344, 1996.

FERREIRA JÚNIOR, S. As finanças públicas nos estados brasileiros: uma avaliação da execução orçamentária, no período de 1995 a 2004. 2006. 192 f. Tese (Doutorado em Economia Aplicada) - Universidade Federal de Viçosa, Viçosa, 2006. Disponível em: <http://locus.ufv.br/handle/123456789/145>. Acesso em: 10 fev. 2016.

FLATTERS, F.; HENDERSON, V.; MIESZKOWSKI, P. Public goods, efficiency and regional fiscal equalization. Journal of Public Economics, v. 03, n. 2, p. 99-112, 1974.

FRANCISCO NETO, J. Responsabilidade fiscal e gasto público no contexto federativo. Tese (Doutorado em Direito) - Universidade de São Paulo, São Paulo, 2009. Disponível em: <http://www.teses.usp.br/teses/disponiveis/2/2133/tde-08072011-133248/pt-br.php>. Acesso em: 2 fev. 2016.

GARNAUT, R.; FITZGERALD, V. Issues in commonwealth-state funding. Canberra, 2002. Disponível em: < https://blogs.unimelb.edu.au/rossgarnaut/files/2016/01/Issues-inCommonwealth-State-Funding-AFR-2002-2idge54.pdf> . Acesso em: 07 jun. 2016.

HANSEN, E. B. Threshold effects in non-dynamic panels: estimation, testing and inference. Journal of Econometrics, v. 93, p. 345-368, 1998.

INSTITUTO BRASILEIRO DE GEOGRAFIA E ESTATÍSTICA. SIDRA - Sistema IBGE de Recuperação Automática. Disponível em: < http://sidra.ibge.gov.br/home/ipca15/brasil>. Acesso em: 17 jan. 2015. 
INSTITUTO DE PESQUISA ECONOMICA APLICADA. Disponível em: < http://www. ipeadata.gov.br/>. Acesso em: 17 jan. 2015.

JOHNSON, R. A.; WICHERN, D. W. Applied multivariate statistical analysis. Englewood Clifs: Prentice-Hall, 1988.

KRAEMER, M. Intergovernmental transfers and political representation: empirical evidence from Argentina, Brazil and Mexico. Washington: Inter-American Development Bank, 1997. (IDB Working paper n. 285). Disponível em: <https://www.researchgate.net/ publication/23531489_Intergovernmental_Transfers_and_Political_Representation_ Empirical_Evidence_from_Argentina_Brazil_and_Mexico $>$. Acesso em: 07 jun. 2016.

MENDES, M.; MIRANDA, B. R.; COSIO, B. F. Transferências intergovernamentais no Brasil: diagnóstico e proposta de reforma. Brasília: Consultoria Legislativa do Senado Federal, 2008. (Textos para discussão n. 40). Disponível em: < https://www12.senado.leg.br/ publicacoes/estudos-legislativos/tipos-de-estudos/textos-para-discussao/td-40-transferenciasintergovernamentais-no-brasil-diagnostico-e-proposta-de-reforma > . Acesso em: $15 \mathrm{dez}$. 2016.

MUSGRAVE, A. R. Teoria das finanças públicas: um estudo da economia governamental. São Paulo: Atlas, 1976.

OATES, E. W. An essay on fiscal federalism. Journal of Economic Literature, v. 37, n. 3, p. 1120-1149, 1999.

ORGANISATION FOR ECONOMIC CO-OPERATION AND DEVELOPMENT. Fiscal equalisation in OECD countries. [S. 1]: OECD, 2007. (Working paper n. 4). Disponível em: $<$ https://www.oecd.org/ctp/federalism/39234016.pdf>. Acesso em: 16 jun. 2016.

REINGEWETZ, Y. Fiscal descentralization: a survey of the empirical literature. Munich: Munich University, 2014. (MPRA Paper n. 59889).

SHAH, A. Principles and the practice of fiscal equalization transfers with special emphasis on solidarity or Robin Hood programs. [S. 1], 2014. Disponível em: <http://www.worldbank.org/ content/dam/Worldbank/Event/ECA/Poland/pl-fiscal-equalization-anwar-shah.pdf $>$. Acesso em: 16 jun. 2016.

TIEBOUT, M. C. A pure theory of local government expenditure. Journal of Political Economy, v. 64, n. 5, p. 416-424, 1956.

WANG, Q. Fixed-effect panel threshold model using Stata. The Stata Journal, v. 15, n. 1, p. 121-134, p. 121-134, 2015.

WURZEL, E. Consolidating germany's finances. [S. 1]: OECD, 2003. (OECD Working Papers n. 366). 


\section{Apêndice A - Dendrograma da Análise de Cluster}

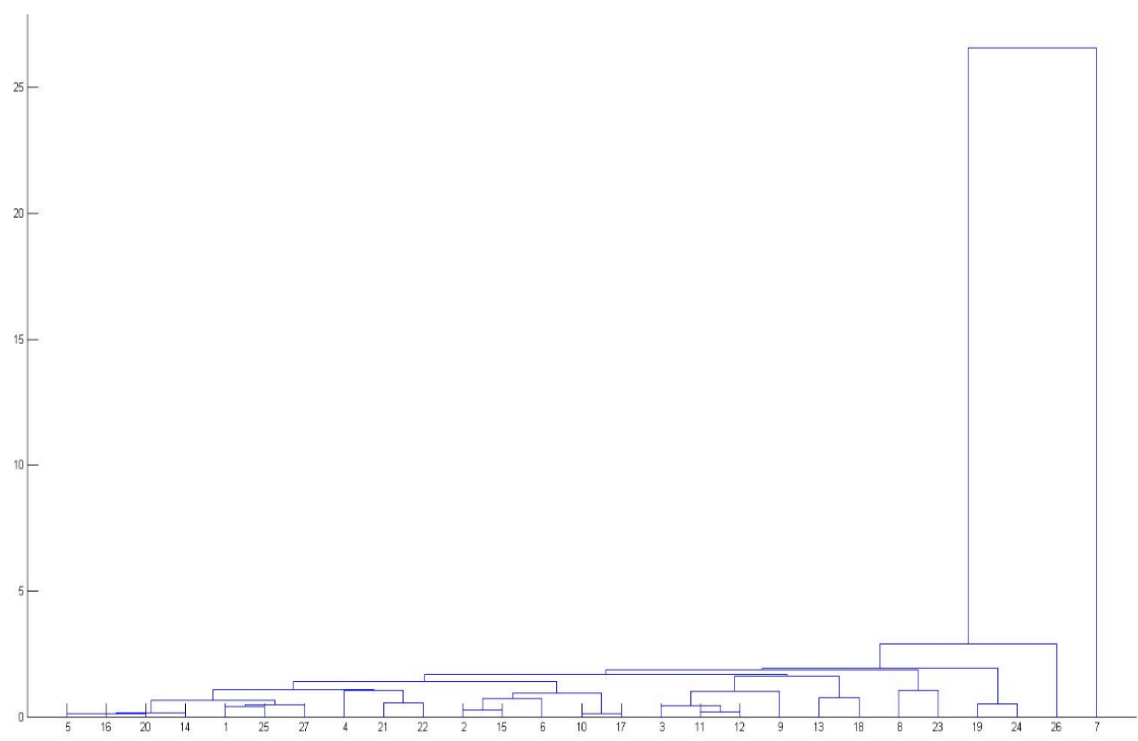

Fonte: Elaboração própria.

Recebido em: 08/05/2017.

Aceito em: 06/02/2018. 